\title{
Обременительные договоры: экономика и отчетность
}

\section{О. В. Рожнова ${ }^{1 凶}$}

${ }^{1}$ Финансовый университет при Правительстве Российской Федерации, пр. Ленинградский, 51, 185910, Москва, Российская Федерация

Для цитирования: Рожнова О. В. Обременительные договоры: экономика и отчетность // Вестник Воронежского государственного университета. Серия: Экономика и управление. 2020. № 2. С. 131-143. DOI: $10.17308 /$ econ.2020.2/2896

Предмет. Проблема убыточных договоров существует в бизнесе всегда, причем в периоды кризисов, стагнации она становится особенно важной. Убыточные договоры уменьшают главный целевой показатель компании - прибыль. Однако их влияние на бизнес не всегда однозначно, и не менее важным, чем реальный факт получения убытка, для экономического субъекта является сам факт и характер его информационного представления для всех заинтересованных сторон. Даже в рамках одной и той же системы учета и отчетности в разные периоды ее развития такие договоры могут отражаться по-разному. Система МСФО выделяет среди убыточных договоров обременительные, определяя для них особый порядок учетного отражения. В данной статье рассматриваются прежде всего именно такие договоры, включая принципы их учета, их связь с элементами отчетности, а также контент раскрываемой о них отчетной информации.

Цели. Комплексное авторское исследование проблемы учетного отражения обременительных договоров. Выработка новых предложений в отношении представления информации об обременительных договорах в отчетности стейкхолдерам для повышения качественного уровня их информированности за счет гармонизации финансовой и нефинансовой отчетности.

Методология. В процессе исследования проблемы учетного представления обременительных договоров (а также иных убыточных договоров) использовались методы логического анализа, методы абстрагирования, аналогий, группировки.

Результаты. Принципы и правила учетного представления обременительных договоров (а также убыточных договоров) в финансовой отчетности не позволяют ее пользователям составить полную картину влияния таких договоров на показатели деятельности отчитывающихся компаний. Пользователи не получают информации о рисках, которые несут в себе обременительные (а также убыточные) договоры, и рисках, которые данные договоры нивелируют. Правила формирования финансовой отчетности в части таких договоров не всегда подробны и оставляют возможность для различных толкований, что приводит к несопоставимости отчетных данных, также в правилах весьма ограничены требования к раскрытию информации по обременительным договорам.

Выводы. Сделан вывод о необходимости представления стейкхолдерам более полной информации об обременительных договорах на основе использования консолидированных данных финансовой и нефинансовой отчетностей, раскрытия рисков, вызванных обременительными договорами и нивелируемых ими; а также о полезности аналогичных раскрытий в отношении убыточных договоров, подготовленных и структурированных методом профессионального суждения и ответственности.

Ключевые слова: обременительные договоры, оценочные обязательства, финансовая и нефинансовая отчетность.

\section{Введение}

В XXI в. весь мир столкнулся с различными кризисными ситуациями, вызванными политическими, экономическими, экологическими и социальными проблемами. Россия не стала исключением. В настоящее время вместе с другими странами она переживает тяжелейшую ситуацию, связанную с пандемией. В ус-

(C) Рожнова О. В., 2020

Вестник ВГУ. Серия: Экономика и управление. 2020. № 2. С. 131-143 ловиях кризисных явлений возрастает вероятность для многих экономических субъектов продуцировать убыточные договоры, в том числе и обременительные. Учитывая сложный период в экономике России, обусловленный санкциями, трудностями перехода к инновационному направлению развития и цифровым технологиям, скачками цен на нефть и газ и другими причинами, нельзя не отметить по- 
вышение значимости проблемы учетного отражения убыточных, и прежде всего обременительных, договоров. Тема представления пользователям информации об обременительных договорах, подготовленной по Международным стандартам финансовой отчетности (далее - МСФО) или в Федеральных стандартах бухгалтерского учета (далее - ФСБУ), изучается, как правило, в контексте темы оценочных обязательств. Т. Ю. Дружиловская указывает на необходимость «обратиться к проблемам учета оценочных обязательств» и в МСФО, и в РСБУ [5, с. 2]. В работе Л. Н. Герасимовой приводится пример в отношении создания оценочного обязательства по обременительному договору и отмечается, что оценочное обязательство, играя важную роль в формировании результата организации, снижает и предотвращает риски [4, с. 17]. Л.И. Куликова рассматривает отражение оценочных обязательств в РСБУ [12], А. П. Воеводин и С. Е. Хрущев исследуют способы определения оценочного обязательства на основе теории вероятности [3]. И. А. Лисовская, Н. Г. Трапезникова отмечают наличие элементов «принятия решений» при определении оценочных обязательств, в том числе и в отношении обременительных договоров [15, с. 69]. Концептуальные основы признания оценочных обязательств подробно исследованы Д. А. Прокоповичем [18]. И. Е. Мизиковский и Е. П. Поликарпова предлагают систему счетов аналитического учета оценочных обязательств [16, с. 40]. Т.А. Лаврухиной выявлена зависимость достоверности отчетности от применения при формировании оценочных обязательств профессионального суждения [13, с. 105]. Наиболее актуальное и заслуживающее внимание исследование в отношении оценочных обязательств содержится, на наш взгляд, в работе Л. Р. Козловой, предлагающей представлять в финансовой отчетности (как по МСФО, так и по РСБУ) раскрытие структуры оценочных обязательств [9, с. 102]. Среди работ практического характера следует отметить статьи А. Б. Богопольского в части обременительных договоров при операциях с покупателями [2] и К. В. Кулаги в отношении правил учета обременительных договоров и выделения существующих сложных и спорных вопросов [11]. В работе О. С. Федоровой, О. Л. Харалгиной, М. В. Королевой, П. С. Алпатова и А. В. Брызгалина проведен сравнительный анализ отражения обременительных договоров согласно МСФО и РСБУ [23].

В то же время в юридической научной литературе имеется целый ряд трудов, в которых освещаются непосредственно связанные с обременительными договорами правовые аспекты. Например, О. И. Мягковой проведен анализ несправедливых договорных условий в российском гражданском праве [17]. А. Ф. Пьянкова указывает, что ничтожность несправедливых условий договора признается большинством зарубежных стран [19].А. Ю. Лисицкая как один из критериев несправедливости условий договора выделяет содержательный признак, заключающийся в том, что условие, не противоречащее закону, тем не менее является для одной стороны обременительным [14]. А. В. Кузьмина всесторонне исследует доктрину защиты слабой стороны от навязывания явно обременительных условий при переговорном неравенстве и приходит к выводу об отсутствии достаточно ясного ее законодательного закрепления [10]. Проведенный анализ научных трудов по теме исследования показал, что во многих из перечисленных работ, как в области права, так и в области учета, в различных направлениях и в различной степени исследуются обременительные договоры, регулируемые на международном уровне МСФО (IAS) 37 «Оценочные обязательства, условные обязательства и условные активы» ${ }^{1}$ и на российском уровне ПБУ $8 / 2010$ «Оценочные обязательства, условные обязательства и условные активы» ${ }^{2}$.

Однако в научной литературе мало внимания уделено обременительным договорам в свете Концептуальных основ МСФО; их воздействия на результаты деятельности и финансовое положение организаций; а в целом отсутствует обобщенный анализ правил их представления в отчетности. В связи с этим целью статьи является комплексное исследование проблемы учетного отражения обреме-

${ }^{1}$ МСФО (IAS) 37 «Оценочные обязательства, условные обязательства и условные активы»(введен в действие на территории Российской Федерации Приказом Минфина России от 28.12.2015 № 217н) (ред. от 05.08.2019).

2 Положение по бухгалтерскому учету «Оценочные обязательства, условные обязательства и условные активы» (ПБУ 8/2010)", утверждено Приказом Минфина России от 13.12.2010 № 167н (ред. от 06.04.2015) (зарегистрировано в Минюсте России 03.02.2011 № 19691). 
нительных договоров, позволяющее сделать новые предложения в отношении представления информации об обременительных договорах в отчетности стейкхолдерам для повышения качественного уровня их информированности за счет гармонизации финансовой и нефинансовой отчетности. В связи с указанной целью были поставлены задачи: рассмотреть обременительные договоры в контексте Концептуальных основ МСФО; проанализировать историю принципов и правил их учетного отражения; рассмотреть их в части отчетной информации о рисках; сделать предложения о раскрытии информации по обременительным договорам в финансовой отчетности и координации этой информации с нефинансовой отчетностью. Научная гипотеза исследования была сформулирована следующим образом: информация об обременительных договорах, являющихся результатом реализации определенных рисков и генераторами новых рисков, приобретает должный уровень информативности для пользователей при применении для ее формирования метода консолидированного профессионального суждения бухгалтера и руководителя на базе сведений, содержащихся в финансовой и нефинансовой отчетностях.

\section{Материалы и методы исследования}

Исследование отражения обременительных договоров в отчетности построено на изучении положений их учетного отображения в системе МСФО, в том числе в Концептуальных основах этой системы (далее - Концептуальные основы) ${ }^{3}$; в правилах MCФО (IAS) 37 «Оценочные обязательства, условные обязательства и условные активы»; правилах других международных стандартов, в той или иной мере затрагивающих рассматриваемую тему; а также иных документах Совета по Международным стандартам финансовой отчетности (СМСФО).

Анализ Концептуальных основ МСФО показывает, что для целей формирования финансовой отчетности договор играет важную роль, являясь источником прав и обязанностей, которые служат базой таких элементов отчетности, как активы и обязательства. Эти права и обязанности могут быть взаимозави-

\footnotetext{
${ }^{3}$ Концептуальные основы представления финансовых отчетов. URL: http://www.minfin.ru/
}

симыми, тогда они не разделяются и формируют единую первооснову для образования либо актива, либо обязательства. Взаимозависимые права и обязанности, например, присущи договору к исполнению, по которому отражение актива (или обязательства) в Отчете о финансовом положении происходит после проведения процедуры его признания и оценки, а также установления факта наличия или отсутствия обремененности договора (рис. 1).

Договор к исполнению - неисполненный договор - т. е. договор или его часть одинаково не исполненные. Например, ни одна обязанность не выполнена ни одной стороной или обязанности выполнены сторонами на одном уровне. В договоре к исполнению одновременно существуют право и обязанность обмена экономическими ресурсами. В нем заключено будущее экономических субъектов, так как договор еще не завершен. В связи с этим так важно для самих субъектов и их стейкхолдеров то, как данный договор будет представлен в отчетности, т. е. какие активы или обязательства будут по нему признаны. Если активы сулят будущие выгоды, то обязательства - это будущий отток выгод. При ожидании невыгодного обмена по договору к исполнению ожидается убыток, т. е. обязанность превышает права, и такой договор называется убыточным. Обременительные договоры представляют собой особый вид убыточных договоров, подробно описанный в МСФО (IAS) 37, где для представления обременительных договоров в отчетности есть соответствующие правила. В других международных стандартах такой договор упоминается, как правило, в плане необходимости обращения к положениям MCФО (IAS) 37. Например, согласно МСФО (IAS) 41 «Сельское хозяйство ${ }^{4}$ к обременительным договорам на продажу биологических активов и сельскохозяйственной продукции следует применять MCФО (IAS) 37. В MСФО (IFRS) 16 «Аренда»5 установлено, что МСФО 37 необходимо использовать для договоров аренды, которые становятся обременительными еще до начала

${ }^{4}$ МСФО (IAS) 41 «Сельское хозяйство» (введен в действие на территории Российской Федерации приказом Минфина России от 28.12.2015 № 217н) (ред. от 11.07.2016).

${ }^{5}$ MCФO (IFRS) 16 «Аренда» (введен в действие на территории Российской Федерации Приказом Минфина России от 11.06.2016 № 111н) (ред. от 16.09.2019). 


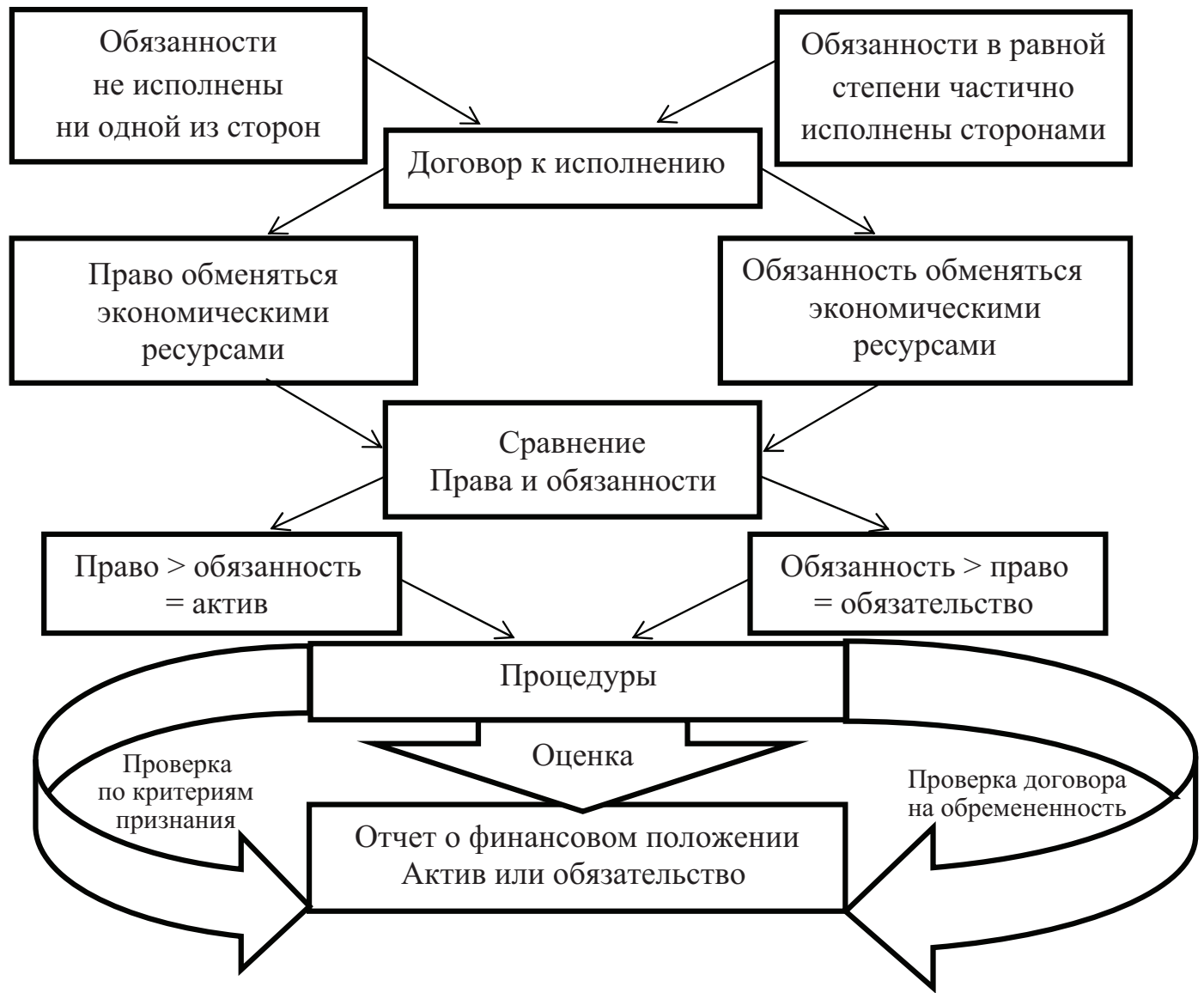

Puc. 1. Признание договора к исполнению и его отражение в ОФП

аренды, и ставших обременительными договоров, согласно которым аренда является или краткосрочной, или с низкой стоимостью базового актива. В то же время в МСФО (IFRS) 15 «Выручка по договорам с покупателями» ${ }^{6}$ договоры, являющиеся обременительными, не упоминаются, но на них распространяются правила МСФО (IAS) 37, что определено именно в этом стандарте. В МСФО (IFRS) $3^{7}$ «Объединение бизнесов» приводится понятие обременительного договора в контексте эффективного урегулирования существовавших ранее договорных отношений между приобретателем и объектом приобретения при объединении бизнесов. Отметим, что понятие обременительного договора используется

${ }^{6} \mathrm{MCФO} \mathrm{(IFRS)} 15$ «Выручка по договорам с покупателями» (введен в действие на территории Российской Федерации Приказом Минфина России от 27.06.2016 № 98н) (ред. от 14.09.2016) (с изм. и доп., вступ. в силу с 01.01.2019).

${ }^{7}$ MCФО (IFRS) 3 «Объединения бизнесов» (введен в действие на территории Российской Федерации Приказом Минфина России от 28.12.2015 № 217н) (ред. от 22.01.2019). также в MCФО (IFRS) 17 «Договоры страхования» 8 , однако в этом стандарте используется иная трактовка этого понятия, отражающая специфику данного вида деятельности.

Для исследования использовались научные публикации не только учетно-экономической направленности, но также тесно связанной с ней юридической. В научных работах российских авторов, исследующих учетную сферу, тема отражения обременительных договоров, как уже отмечалось, не нашла должного отражения. Упоминание обременительных договоров встречается во многих трудах, однако глубокого комплексного исследования проведено не было, очевидно, в силу не столь серьезного восприятия экономических проблем, связанных с этими договорами, и не большого объема учетных требований в отношении них в МСФО (и соответственно, в РСБУ). В то же время, во-первых, убыток по этим договорам может ока-

${ }^{8}$ MCФО (IFRS) 17 «Договоры страхования» (введен в действие на территории Российской Федерации Приказом Минфина России от 04.06.2018 № 125н). 
зывать значительное влияние на бизнес; и, во-вторых, убыток по ним может быть и не получен по итогам судебного разбирательства. В российском гражданском праве выделяются договоры присоединения, т. е. договоры, по которым одна сторона не участвует в составлении договора, а только присоединяется к нему. Договоры присоединения, являющиеся обременительными для присоединившейся к договору стороны, могут оспариваться этой стороной согласно Гражданскому кодексу РФ9 ${ }^{9}$ это положение распространяется также и на предпринимательские договоры ${ }^{10}$. Причем, как отмечает А. Ф. Бакулин, договор присоединения уже трактуется не узко, а как общая правовая категория договор с неравенством переговорных возможностей ${ }^{11}$ [1]. В качестве слабой стороны могут выступать субъекты предпринимательской деятельности. А. А. Томтосов, объясняя слабость стороны предпринимательского договора, перечисляет следующие факторы, ее обусловливающие: рыночная власть, асимметрия информации, асимметрия профессионализма [22]. Признание слабой стороной, участвующей в коммерческом договоре присоединения в качестве присоединившейся стороны, является презюмируемым и не требует объяснений. Но и без процедуры присоединения слабая сторона может начать судебное разбирательство, предъявляя убедительные доказательства прохождения ее ознакомления с проектом договора в условиях существовавших ограничений в его обсуждении; предъявленных требованиях к контрагенту о дополнительных сведениях о существе, неопределенностях и рисках по этому договору.

Была проанализирована финансовая отчетность российских крупнейших российских предприятий в отношении раскрытия информации о подобных договорах. В консолидиро-

${ }^{9}$ Гражданский кодекс Российской Федерации : Часть первая - четвертая : [принят Гос. Думой 23 апреля 1994 года, с изм. и доп. по состоянию на 16 декабря 2019 г.] // СЗ РФ. 1994. № 22. Ст. 428.

10 О внесении изменений в часть первую Гражданского кодекса Российской Федерации : федеральный закон от 8 марта 2015 г. № 42-ФЗ // СЗ РФ. 2015. № 10. Ст. 1412.

${ }^{11}$ Гражданский кодекс Российской Федерации: Часть первая - четвертая : [принят Гос. Думой 23 апреля 1994 года, с изм. и доп. по состоянию на 16 декабря 2019 г.] // СЗ РФ. 1994. № 22. П. 3. Ст. 428. ванной финансовой отчетности по МСФО за 2018-2019 гг. крупнейших российских компаний ПАО «Газпром» ${ }^{12}$, ПАО «Роснефть» ${ }^{13}$, ПАО «Норильский Никель» ${ }^{14}$, ПАО «РЖД»15 наличия обременительных договоров не зафиксировано.

Методами исследования послужили метод абстрагирования, общелогические методы (анализ и синтез), диалектический метод, методы наблюдения, аналогий, группировки.

\section{Обсуждение результатов}

Финансовая отчетность отражает как уже полученный результат деятельности компании, так и ожидаемый результат посредством представления информации об активах, обязательствах и экономических рисках. Завершенные к отчетной дате убыточные договоры, хотя и могут создавать экономические риски, сами по себе учетные риски уже генерировать не способны, т. е. они уже не влияют на размер будущей прибыли, не могут вызвать в будущем убыток. Поэтому учетный интерес вызывают договоры к исполнению, т. е. незавершенные, которые несут в себе риски получения в будущем убытка (конечно, для бизнеса важен и риск недополучения прибыли, но на достигнутом уровне развития учета пока не представляется возможным его нивелирование в финансовой отчетности из-за значительной субъективности).

Как принято в МСФО при использовании исторической модели, учетная процедура снятия подобного риска состоит в немедленном признании ожидаемого убытка. Такой подход остался в правилах отражения убытка в отношении обесценивавшихся активов MCФО (IAS) 2 «Запасы» ${ }^{16}$, MСФО (IAS) 16 «Ocновные средства» ${ }^{17}$, MСФО (IAS) 38 «Немате-

${ }^{12}$ URL: https://www.gazprom.ru/investors/disclosure/ reports/2019/

${ }^{13}$ URL: https://www.rosneft.ru/upload/site1/document_ cons_report/Rosneft_FS_12m2019_RUS.pdf

${ }_{14}$ URL: https://WwW.nornickel.ru/investors/reportsand-results/

${ }^{15}$ URL: https://old-ir.rzd.ru/static/public/ru?STRUCTURE_ $\mathrm{ID}=32 \# 1$

${ }^{16}$ MCФО (IAS) 2 «Запасы» (введен в действие на территории Российской Федерации Приказом Минфина России от 28.12.2015 № 217н) (ред. от 11.07.2016).

17 MCФО (IAS) 16 «Основные средства» (введен в действие на территории Российской Федерации Приказом Минфина России от 28.12.2015 № 217н) (ред. от 11.07.2016). 
риальные активы» ${ }^{18}$, МСФО (IAS) 36 «Обесценение активов» ${ }^{19}$, МСФО (IFRS) 9 «Финансовые инструменты ${ }^{20}$ и в отношении немедленного отражения соответствующих ожидаемых обязательств в МСФО (IAS) 37.

Однако в МСФО 37 правила создания оценочного обязательства распространяются лишь на договоры исполнения, которые являются обременительными. Но обременительные договоры не равны убыточным, они представляют только их часть. Убыточными являются договоры, по которым все расходы превышают все доходы по договору. В практике бизнеса договоры могут быть первоначально убыточными и далее продолжать оставаться таковыми. Первоначально убыточные договоры заключаются по различным причинам, среди которых целесообразно выделить следующие четыре обобщенные группы:

- планирование (ожидаемая возможность) получения будущих опосредованных выгод, никаким образом не обозначенных в договоре;

- ошибки в расчетах доходов и расходов по договорным операциям;

- умысел в целях получения личной выгоды каким-либо лицом (группой лиц);

- принуждающая ситуация (например, кризис).

Но договоры изначально могут и не быть убыточными, становясь таковыми уже после их заключения. Для договора, чье выполнение происходит в течение нескольких отчетных периодов, ожидаемое состояние убыточности может быть переменным. Правила отражения убыточных договоров с покупателями не отличаются от правил отражения прибыльных и регламентируются МСФО 15 «Выручка по договорам с покупателями», в соответствии с которым убыток признается только фактически заработанный на отчетную дату (но исходя из будущей ситуации ожидаемой выручки).

${ }^{18}$ МСФО (IAS) 38 «Нематериальные активы» (введен в действие на территории Российской Федерации Приказом Минфина России от 28.12.2015 № 217н) (ред. от 30.10.2018) (с изм. и доп., вступ. в силу с 01.01.2019).

${ }^{19}$ МСФО (IAS) 36 «Обесценение активов» (введен в действие на территории Российской Федерации Приказом Минфина России от 28.12.2015 № 217н) (ред. от 27.06.2016) (с изм. и доп., вступ. в силу с 01.01.2018).

${ }^{20}$ MCФО (IFRS) 9 «Финансовые инструменты» (введен в действие на территории Российской Федерации в редакции 2014 года Приказом Минфина России от 27.06.2016 № 98н) (ред. от 16.09.2019).
Ранее, согласно правилам МСФО (наглядный пример МСФО 11 «Договоры подряда»), в случае, когда договор был убыточным, весь ожидаемый убыток признавался как результат работы по данномудоговору. Хотя этот убыток и не являлся оценочным обязательством, но тем не менее будущие риски он снимал в целом так же, как и оценочное обязательство. В этом проявлялась ассиметрия принципа осмотрительности, который уже на концептуальном уровне трактовался как направленный на немедленное признание ожидаемых убытков в показателе прибыль/убыток, но ни в коем случае не подобное признание ожидаемой прибыли. Трактовка этого принципа изменилась в Концептуальных основах, а также и его применение, например, в правилах MCФO (IFRS) 15. По простым убыточным договорам весь ожидаемый убыток не отражается, такой подход сохранен только для обременительных договоров, которые для целей учета выделяются в самостоятельную группу и подчиняются «старой» трактовке принципа осмотрительности.

Идентификация обременительного договора связана не с ожидаемыми фактическими затратами, а только с частью этих затрат, являющихся неизбежными для выполнения обязанностей по договору. Обременительным признается договор, по которому неизбежные затраты на выполнение обязанностей больше ожидаемых от его исполнения экономических выгод ${ }^{21}$. Обременительные договоры изучаются в различных областях знаний, в том числе юриспруденции и учете. Следует отметить, что обременительные договоры могут стать причиной судебных разбирательств, подобные договоры, относящиеся к договорам присоединения ${ }^{22}$, часто рассматриваются в научной юридической литературе [17-22].

В области учета обременительные договоры, как правило, исследуются в связи с оценочными обязательствами, чей порядок создания регламентируется МСФО (IAS) 37. Правила данного стандарта распространяются только

${ }^{21}$ МСФО (IAS) 37 «Оценочные обязательства, условные обязательства и условные активы» (введен в действие на территории Российской Федерации Приказом Минфина России от 28.12.2015 № 217н) (ред. от 05.08.2019). П. 10.

${ }^{22}$ Гражданский кодекс Российской Федерации (часть первая) от 30.11.1994 № 51-ФЗ (ред. от 16.12.2019). Ст. 428. 
на обременительные договоры к исполнению. Различные аспекты учетного представления обременительных договоров и оценочных обязательств нашли отражение в научных и научно-практических работах [5-9]. Авторы отмечают следующие проблемные вопросы в учете обременительных договоров: неоднозначность определения договора к исполнению; непроработанность в МСФО понятия «неизбежные затраты»; неоднозначность вопроса о создании оценочного обязательства не по обременительному, но убыточному договору; неясность ситуации, в которой неизбежные затраты меньше экономических выгод, но организация все равно будет нести не наименьшие затраты, а наибольшие, что является выгодным для бизнеса [11]. Над вопросом понятия неизбежных затрат СМСФО работал, проводя его всестороннее исследование, так как в МСФО не должна существовать противоречивость между трактовкой, в данном случае затрат, которые признаются как первоначальная оценка (капитализируемые затраты), например запасов (MСФО (IAS) 2), или затрат, относящихся к договору в покупателями (MCФО (IFRS) 15), и трактовкой затрат при идентификации обременительного договора. Любое решение по капитализации не однозначно, в любом случае есть аргументы как «за», так и «против». Достижение соответствия между стандартами не должно приводить к признанию будущих операционных убытков, что запрещено правилами MСФО (IAS) 37. В МСФО (IAS) 37 установлено, что неизбежные затраты по договору равны минимальным чистым затратам на выход из договора, которые в свою очередь определяются как наименьшая величина из суммы затрат на исполнение договора и совокупной стоимости всех компенсаций и штрафов, которые следует уплатить при неисполнении договора. Проблема связана с установлением суммы затрат на исполнение договора, как правило, это такие затраты, которые не возникли бы в случае отсутствия данного договора, т. е.дополнительные. При их установлении сложность может возникать с дополнительными затратами, являющимися распределяемыми накладными затратами ${ }^{23}$, для решения следует придерживаться п. 96, 97, 98 МСФО (IFRS) 15. Суще-

${ }^{23}$ Investopedia, WILL KENTON «Onerous Contract», Updated Apr 1, 2019 (дата обращения: 14.04.2020). ствует также процедура объединения юридических договоров в один экономически признаваемый договор согласно МСФО 15 или, напротив, разделения одного юридического договора на несколько экономически признаваемых договоров. В этих ситуациях присутствует метод профессионального суждения. Соответственно, существует риск субъективности при определении неизбежных затрат по договору а, следовательно, неверному отражению затрат по нему и ошибочному непризнанию или ошибочному признанию оценочного обязательства.

Кроме перечисленных проблем учета, считаем необходимым выделить также следующие:

- во-первых, общую неразработанность вопросов обременительных договоров как с общеэкономической точки зрения, так и с учетной;

- во-вторых, проблему сложности принятия во внимание косвенных выгод для получения достоверной оценки обременительных договоров, т. е. проблему учетной единицы;

- в-третьих, проблему раскрытий информации, уместной и достоверной в отношении таких договоров для пользователей отчетности;

- в-четвертых, проблему создания возможности для стейкхолдеров прослеживать связи между показателями в финансовой отчетности об оценочных обязательствах, обусловленных обременительными договорами, и информацией, содержащейся в нефинансовой отчетности.

Касаемо первой проблемы следует отметить, что требуют осмысления значение обременительных договоров для экономических субъектов и экономики в целом на различных этапах ее развития. В кризисные периоды количество обременительных договоров может увеличиваться, как и их доля в общем числе заключаемых договоров. Влияние обременительных договоров на поддержание деловой активности требует изучения, в экономической ситуации, связанной, например, с глобальной блокировкой экономики, вызванной пандемией, это особенно актуально. С позиции экономических субъектов такие договоры следует считать зоной риска. Причем в эту зону логично отнести также и договоры, находящиеся на грани обременительных, т. е. имеющие высокую вероятность стать обременительными при наиболее пессимистичном развитии событий. Рассмотрение вопроса о создании оценочного обязательства по обре- 
менительным договорам предполагает использование метода профессионального суждения, который требуется уже на стадии идентификации обременительного договора. Соответственно, риск субъективности, возникая как учетный риск, вызывает иные риски, риски получения пользователями отчетности недостоверной информации, риски неправильных решений, принятых пользователями на основе этой информации, риски неэффективного развития экономики. Цель как можно более объективного учетного отражения обременительных договоров связана с целью изучения их экономического значения и требует мониторинга их состояния, прогноза их появления и разработки как можно более полных классификаций этих договоров по различным признакам. Так, например, необходима детальная классификация по признаку причины их возникновения (по сравнению с приведенными четырымя группами). Значительный интерес для учетной науки и экономики в целом представляет выделение и анализ внешних и внутренних причин заключения обременительных договоров экономическими субъектами и соотношение этих причин на современной стадии развития экономики. Как показало второе десятилетие XXI в., воздействие внешних причин, экологических, социальных, политических, на рост количества обременительных договоров может быть достаточно серьезным.

Если определение неизбежных затрат на договор к исполнению вызывает понятные трудности и требует от организации разработки соответствующих внутренних документов, регламентирующих состав неизбежных затрат и поясняющих их обоснованность, то вопрос о косвенных выгодах, получаемых от заключения обременительного договора, еще более сложен. Например, обременительный договор заключается для получения в будущем выгодных заказов. Однако определить эти будущие выгоды весьма затруднительно, субъективность в данном случае может оказаться существенной. Кроме того, единицей учета в данном случае выступает конкретный договор, в котором косвенные выгоды могут быть не обозначены либо обозначены весьма условно в виде некоторых намерений. В этом случае, хотя для организации экономически договор может и не являться обременительным, но из-за невозможности достоверного определения экономических выгод организация будет должна отразить в настоящее время расходы (а также сделать проверку на обесценение активов, используемых для выполнения обременительного договора, которая требуется перед созданием оценочного обязательства по нему). Определенная субъективность существует также и при расчете прямых выгод. С введением МСФО 15 «Выручка по договорам с покупателями» при расчете выручки по договору учитывается не только фиксированное вознаграждение, но также и переменное. Расчет суммы выручки стал еще более тесно связан с профессиональным суждением. Оно необходимо и для установления компонента финансирования, и для вычисления переменной части выручки.

Проблема раскрытия информации об обременительных договорах приоритетна уже в силу того, что в настоящее время приоритетны раскрытия как составляющая часть финансовой отчетности. Всем стейкхолдерам важно понимать, почему организация заключила обременительный договор, ведущий к существенным убыткам. При этом кумулятивный эффект также играет роль - у организации может быть много обременительных договоров, каждый из которых приносит незначительный убыток, но сумма потерь по всем таким договорам существенна. Пользователю, с одной стороны, интересно, какие риски возникают от обременительных договоров, а с другой - еще более интересно, какие риски организация, возможно, пытается ликвидировать при помощи заключения обременительных договоров.

Отмеченная проблема раскрытий перетекает в проблему, указанную как четвертая. Как показывают многие исследования, и в частности отмечает О. В. Ефимова, пользователи отчетности получают слишком пространные отчеты - финансовую отчетность и различные наборы других отчетов либо единую нефинансовую отчетность, подготовленную во многих случаях по несопоставимым для разных организаций стандартам $[7 ; 8]$. При этом часто у экономического субъекта отсутствует единая концепция «Информации для пользователей» и, соответственно, трудно проследить связь между сведениями, содержащимися в разных отчетах, хотя тенденция на объединение финансовой и нефинансовой отчетностей уже 
Обременительные договоры: экономика и отчетность

существует, что отмечалось автором статьи еще в 2018 г. [20]. Необходимо, чтобы информация об обременительных договорах (а также о значительных убыточных договорах) содержалась в требующемся для пользователей объеме, была логично структурирована и хорошо визуализирована; чтобы были указаны в одном месте ее расположение по отчетам и примечаниям и наиболее удобный путь ее отслеживания. Разработкой репрезентативных раскрытий об обременительных договорах должны заниматься и руководство организации, и соответствующие специалисты, в том числе по коммуникациям с пользователями, добиваясь правильного восприятия последними получаемых данных (исследованию восприятия информации посвящена статья О. В. Рожновой [21]). Нельзя не согласиться с Д. А. Ендовицким и В. А. Бабушкиным в отношении того, что инвесторам необходима полная и достоверная информация для осуществления «объективной оценки уровня инвестиционной привлекательности хозяйствующего субъекта» [6]. Важной частью этой информации, способствующей улучшению инвестиционного климата страны, на наш взгляд, является информация об обременительных и убыточных договорах, взаимоувязанная в финансовой и нефинансовой отчетностях.

\section{Заключение}

Значение учетного отражения обременительных договоров в условиях кризиса резко возрастает, это также относится и к убыточным договорам.

Область обременительных договоров относится к области рисков. Для пользователей отчетности (включая и руководство самого предприятия) весьма важна информация о том, какие риски снимают обременительные договоры, а какие риски они создают. Полагаем, что степень детализации информации для внешних и внутренних пользователей в этих видах рисков может быть различной, но в то же время считаем, что для внешних пользователей соответствующая информация обязательно должна быть представлена в отчетности.

Новизна исследования состоит в выделении в области учетного отражения обременительных договоров наиболее актуальных в настоящее время проблем: отсутствие достаточно информативной учетной разработан- ности темы отражения в отчетности обременительных договоров; сложность (в связи с неопределенностью) и в то же время важность для пользователей учетного отражения косвенных выгод при оценке факта наличия обременительного договора и точность расчета этих выгод; недостаточность требований правил стандартов к раскрытиям информации в отношении обременительных договоров; отсутствие связи информации об оценочных обязательствах по обременительным договорам в финансовой отчетности и информации в нефинансовой отчетности, которая каким-либо образом коррелирует с последствиями, вызванными этими договорами для развития бизнеса, включая как социальную составляющую этого развития, так и экологическую. Например, в настоящее время связь между экологической проблемой в виде мировой пандемии, безусловно, отразится на объемах обременительных договоров (а также убыточных). Если в некризисных условиях наличие обременительных договоров является, скорее, негативным явлением, то при резком снижении активности бизнеса, сворачивании деятельности заключение обременительных договоров может рассматриваться (в определенных условиях) как фактор снижения рисков.

Научной новизной характеризуются также следующие предложения.

Предложение, помимо направленного на решение рассмотренных проблем внесения изменений и дополнений в правила отражения обременительных договоров в МСФО (ФСБУ), самим экономическим субъектам включить вопросы учетного представления обременительных договоров в свою учетную политику, предусмотрев дополнительные раскрытия, помогающие пользователям понять фактические и ожидаемые результаты деятельности, финансовое положение, движение денежных потоков, риски, взаимосвязь с информацией собственной нефинансовой отчетности.

Необходима инициативная работа отчитывающихся организаций по созданию для стейкхолдеров возможности увидеть и понять взаимосвязь как на уровне нормативных документов, так и на уровне раскрытий финансовой и нефинансовой информации предприятиями в области обременительных договоров 
с областью их юридической трактовки и судебных решений в связи с ними.

Поднятые вопросы касаются не только обременительных, но и убыточных договоров, очевидно, что создание оценочных обязательств по таким договорам может значительно повысить субъективность отчетной информации, в то же время недоведение до пользователей такой информации оказывает негативное воздействие на эффективность их решений и в конечном счете эффективность всей экономики. Соответственно, необходимо продолжение исследований в области представления в отчетности информации по убыточным договорам и рисков, связанных с ними.

Проведенное исследование имеет ограничения, в нем не приведена конкретная статистика по отражению обременительных и убыточных договоров в отчетности российских компаний, исследована отчетность только нескольких наиболее крупных из них. Осознавая этот значительный недостаток, считаем, что использованных методов исследования все же было достаточно для того, чтобы акцентировать внимание научного сообщества на сложных переплетающихся экономических, юридических и учетных вопросах, касающихся обременительных договоров, и обосновать сделанные выводы и предложения.

Еще одним очевидным и выводом, и одновременно предложением является следующее: необходимо продолжать изучение указанной темы, расширяя отмеченные направления ис-

\section{Библиографический список}

1. Бакулин А. Ф. Судебная защита слабой стороны предпринимательского договора / А. Ф. Бакулин // Судья. - 2019. - № 8. - С. 20-27.

2. Богопольский А. Б. Особенности перехода предприятий сельскохозяйственной отрасли на MCФО (IFRS) 15 «Выручка по договорам с покупателями» // Корпоративная финансовая отчетность. Международные стандарты. - 2019. № 3. - C. 21-28.

3. Воеводин А. П. Расчет оценочного обязательства с помощью теории вероятностей / А. П. Воеводин, С. Е. Хрущев // Аудит и финансовый анализ. - 2016. - № 2. - С. 134-139.

4. Герасимова Л. Н. Учет резервов в международной практике / Л. Н. Герасимова // Международный бухгалтерский учет. - 2012. - № 43. - С. 17-21.

5. Дружиловская Т. Ю. Оценочные обязательства и резервы: трактовка и проблемы учета в следования; конкретизируя риски, обусловленные и продуцируемые обременительными и убыточными договорами; предлагая варианты порядка и структуры раскрытия информации о рассматриваемых договорах в финансовой и нефинансовой отчетности; прослеживая связь с областью правовых отношений; разрабатывая принципиально новые визуальные модели для представления пользователям результатов использования компанией обременительных (и убыточных) договоров в своей деятельности.

Кроме того, дальнейшая разработка исследуемой области поможет повысить прозрачность и другой, на первый взгляд, не связанной с ней информации, так как если каждая часть отчетности станет более транспарентной и понятной, то и связи между частями станут более очевидными, то же произойдет и со всей картиной настоящего и будущего экономического субъекта.

\section{Источник финансирования}

Исследование выполнено в рамках фундаментальной научно-исследовательской работы департамента учета, анализа и аудита Финансового университета при Правительстве Российской Федерации «Исследование трендов в бухгалтерском учете, анализе и аудите».

\section{Конфликт интересов}

Авторы декларируют отсутствие явных и потенциальных конфликтов интересов, связанных с публикацией настоящей статьи.

системах российских и международных стандартов / Т. Ю. Дружиловская // Международный бухгалтерский учет. - 2016. - Т. 19, вып. 21, № 4. C. $2-18$.

6. Ендовицкий Д. А. Экономическая природа, понятийный аппарат и виды инвестиционной привлекательности организации / Д. А. Ендовицкий, В. А. Бабушкин // Аудит и финансовый анализ. - 2005. - № 2. - С. 225-230.

7. Ефимова О. В. Корпоративная отчетность как способ взаимодействия с заинтересованными сторонами / О. В. Ефимова // Аудиторские ведомости. - 2015. - № 9. - С. 43-54.

8. Ефимова О. В. Парадигма устойчивого развития: проблемы информационно-аналитического обеспечения / О.В.Ефимова // Инновационное развитие экономики. - 2013. - № 1 (13). - С. 22-31.

9. Козлова Л. Р. Оценочные резервы, условные обязательства и активы в корпоративной отчетно- 
сти компаний / Л. Р. Козлова // Международный бухгалтерский учет. - 2018. - № 1-2. - С. 86-102. DOI: $10.24891 /$ ia.21.1.86.

10. Кузьмина А. В. Формирование доктрины защиты слабой стороны в договорном праве / А. В. Кузьмина // Вестник Пермского университета. Юридические науки. - 2019. - № 4. - С. 698-727. DOI: 10.17072/1995-4190-2019-46-698-727.

11. Кулага Е. В. Отражение убыточных договоров в соответствии с МСФО (IFRS) 15 // Корпоративная финансовая отчетность. Международные стандарты. - 2018. - № 9. - С. 13-22.

12. Куликова Л. И. Оценочные обязательства : признание в учете и оценка / Л. И. Куликова // Бухгалтерский учет. - 2011. - № 5. - С. 30-32.

13. Лаврухина Т. А. Оценочные значения и их влияние на достоверность данных бухгалтерской (финансовой) отчетности / Т. А. Лаврухина // Современная экономика: проблемы и решения. - 2016. № 5(77).-C.105-114.-DOI:10.17308/meps.2016.5/1425.

14. Лисицкая А. Ю. Несправедливые договорные условия в гражданском праве России и за рубежом : сравнительно-правовой анализ / А. Ю. Лисицкая. 2017. - № 6 (82). - С. 140-156.

15. Лисовская И. А. Проблемные строки бухгалтерского баланса : учет и отражение оценочных обязательств / И. А. Лисовская, Н. Г. Трапезникова // Вестник ПГТУ. - 2012. - № 2. - С. 69-77.

16. Мизиковский И. Е. Аналитический учет оценочных обязательств / И. Е. Мизиковский, Д. А. Прокопович // Вестник нижегородского университета им. Н. И. Лобачевского. Серия: Социальные науки. 2018. - № 3 (51). - C. 34-41.
17. Мягкова О. И. Несправедливые договорные условия в российском гражданском праве / О.И. Мягкова // Российский юридический журнал. - 2017. № 2. - С. 99-111.

18. Прокопович Д. А. Резервирование расходов на аудит и другие начисления в финансовой отчетности по МСФО : когда это действительно необходимо? / Д. А. Прокопович // Аудиторские ведомости. - 2014. - № 3. - С. 37-48.

19. Пьянкова А. Ф. Способы защиты прав слабой стороны по договору присоединения / А. Ф. Пьянкова // Защита гражданских прав : избранные аспекты : сб. статей. Сер. «Анализ современного права» / Московский государственный юридический университет имени О. Е. Кутафина. - М., 2017. - С. 57-80.

20. Рожнова О. В. Современные тенденции развития финансовой отчетности / О. В. Рожнова // Учет, анализ, аудит. - 2018. - Т. 5, № 2. - С. 26-35. DOI: 10.26794/2408-9303-2018-5-2-26-35.

21. Рожнова О. В. Пути совершенствования восприятия учетной информации / О.В. Рожнова // Международный бухгалтерский учет. - 2001. № 4. - С. 16-23.

22. Томтосов А. А. Новые подходы к защите слабой стороны договора / А. А. Томтосов // Свобода договора : сб. ст. / отв. ред. М. А. Рожкова. - М., 2016. - С. 364-382.

23. Федорова О. С., Харалгина О. Л., Королева М. В., Алпатов П. С., Брызгалин А. В. Сложные операции и сделки: бухгалтерский учет, документооборот, применение ККТ // Налоги и финансовое право. - 2018. - № 11. - С. 8-147.
Рожнова Ольга Владимировна, доктор экономических наук, профессор, профессор департамента учета, анализа и аудита, Финансовый университет при Правительстве Российской Федерации, Москва, Российская Федерация

E-mail: ORozhnova@fal.ru

ORCID ID: 0000-0002-8955-5904
Поступила в редакцию 16.04.2020

Подписана в печать 06.05.2020 


\title{
Onerous contracts: economics and reporting
}

\section{O. V. Rozhnova ${ }^{1 凶}$}

${ }^{1}$ Financial University under the Government of the Russian Federation

Cite as: Rozhnova, O.V. (2020). Onerous contracts: economics and reporting. Proceedings of Voronezh State University. Series: Economics and Management. 2, 131-143. (In Russ., abstract in Eng.) DOI: 10.17308/econ.2020.2/2896

\begin{abstract}
Importance. The article discusses issues of reflecting onerous contracts in financial reporting prepared in accordance with IFRS and focuses on the impact of these contracts on businesses and the economy as a whole. Main provisions for onerous contracts reporting are analyzed and possible solutions for reporting issues are proposed. Special attention is devoted to importance of professional judgment and mutual correlation of information disclosures in various types of reporting.

Objectives. Present author's research of the problem of accounting reflection of burdensome contracts and develop new proposals for disclosure of onerous contracts in the financial statements.

Methods. Research is based on methods of logic, analogy and statistical analysis.

Results. Stakeholders do not receive relevant information regarding the risks generated by onerous contracts and the risks they offset. The rules for forming financial statements regarding such agreements are not always detailed and leave room for various interpretations.

Conclusions and Relevance. It is concluded that it is necessary to provide stakeholders with more complete information about onerous contracts based on the use of consolidated financial and nonfinancial reporting data, disclosure of risks caused by onerous contracts and mitigated by them. It is concluded that similar disclosures are useful for loss-making contracts prepared and structured using method of professional judgment and responsibility.
\end{abstract}

Key words: onerous contracts, unprofitable contract, provisions, financial and non-financial reporting.

\section{Source of financing}

The research was conducted as part of the fundamental research work of the Department of accounting, analysis and audit of the Financial University under the Government of the Russian Federation «Kesearch of trends in accounting, analysis and audit»

\section{References}

1. Bakulin, A. F. (2019) Sudebnaia zashchita slaboi storony predprinimatelskogo dogovora. Sudia, 8, 20 27. (In Russ.)

2. Bogopolsky, A. B. (2019) Features of the transition of agricultural enterprises to IFRS 15 "Revenue from contracts with customers". Corporate financial reporting. International standards, 3, 21-28. (In Russ.).

3. Voevodin, A. P. \& Khrushchev, S. E. (2016) Calculation of estimated liabilities using probability theory. Audit and financial analysis, 2, 134-139. (In Russ.)

4. Gerasimova, L. N. (2012) Accounting of reserves in international practice. International Accounting, 43, 17-21. (In Russ.)

5. Druzhilovskaya, T. Yu. (2016) Estimated liabilities and provisions: interpretation and accounting

\section{Conflict of interest}

The authors declare the absence of obvious and potential conflicts of interest related to the publication of this article.

issues under the russian and international standards. International Accounting, 19, 21, 4, 2-18. (In Russ.)

6. Endovitsky, D. A. \& Babushkin, V. A. (2005) Ekonomicheskaia priroda, poniatiinyi apparat i vidy investitsionnoi privlekatel'nosti organizatsii. Audit and financial analysis, 2, 225-230. (In Russ.)

7. Efimova, O. V. (2015) Corporate reporting as a method of communication with stakeholders. Auditorskie vedomosti, 9, 43-54. (In Russ.)

8. Efimova, O. V. (2013) Paradigm of sustainable development: issues of information and analytical support. Innovatsionnoe razvitie ekonomiki, 1(13), 2231. (In Russ.)

9. Kozlova, L. R. (2018) Estimated reserves, contingent liabilities and assets in corporate reporting of companies. International Accounting, 1-2. 86-102. (In Russ.) DOI: 10.24891/ia.21.1.86. 
10. Kuzmina, A. V. (2019) Formation of the doctrine of protection of the weak party in contract law. Vestnik Permskogo universiteta. Iuridicheskie nauki, 4, 698-727. (In Russ.) DOI: 10.17072/1995-4190-201946-698-727.

11. Kulaga, E. V. (2018) Reflection of loss-making contracts in accordance with IFRS 15. Corporate financial reporting. International standards, 9, 13-22. (In Russ.).

12. Kulikova, L. I. (2011) Estimated liabilities: recognition and assessment. Bukhgalterskii uchet, 5, 30-32. (In Russ.)

13. Lavrukhina, T. A. (2016) Estimated values and their impact on the reliability of accounting (financial) statements. Modern Economics: Problems and Solutions, 5 (77), 105-114. (In Russ.) DOI: 10.17308/meps. 2016. $5 / 1425$.

14. Lisitskaya, A. Yu. (2017) Nespravedlivye dogovornye usloviia $\mathrm{v}$ grazhdanskom prave Rossii i za rubezhom: sravnitelno-pravovoi analiz. Vestnik VEGU, 6 (82), 140-156. (In Russ.)

15. Lisovskaya, I. A. \& Trapeznikova, N. G. (2012) Challenging lines of the balance sheet: accounting and recognition of estimated liabilities. Vestnik Povolzhskogo gosudarstvennogo universiteta. Seriia ekonomika $i$ menedzhment, 2, 69-77. (In Russ.)

16. Mizikovsky, I. E., \& Polikarpova, E. P. (2018) Analytical accounting of estimated liabilities. Vestnik nizhegorodskogo universiteta im. N.I. Lobachevskogo. Seriia: Sotsialnye nauki, 3(51), 34-41. (In Russ.)

17. Myagkova, O. I. (2017) Unfair contractual terms in Russian civil law. Rossiiskii iuridicheskii zhurnal, 2. 99-111. (In Russ.)

18. Prokopovich, D. A. (2014) Reserving audit expenses and other accruals in financial statements under IFRS: when is it really necessary? Auditorskie vedomosti, 3, 37-48. (In Russ.)

19. Pyankova, A. F. (2017) Ways to protect the rights of the weak party under the accession agreement. Protection of civil rights: selected aspects. Moscow, pp. 57-80. (In Russ.)

20. Rozhnova, O. V. (2018) The Modern Trends of Financial Reporting Development. Accounting, analysis, audit, 5(2), 26-35. (In Russ.) DOI: 10.26794/24089303-2018-5-2-26-35.

21. Rozhnova, O. V. (2001) Options for improving the perception of accounting information. International Accounting, 4, 16-23. (In Russ.)

22. Tomtosov, A. A. (2016) New approaches to the protection of the weak side of the contract. Svoboda dogovora. Moscow, pp. 364-382. (In Russ.)

23. Fedorova, O. S., Kharalgina, O. L., Koroleva, M. V., Alpatov, P. S. \& Bryzgalin, A. V. (2018) Complex operations and transactions: accounting, document management, application of CCP. Taxes and financial law, 11, 8-147. (In Russ.)

Olga V. Rozhnova, Dr. Sci. (Econ.), Prof., Received 16.04.2020 professor of the Department of accounting, anaAccepted 06.05.2020 lysis and audit of Financial University under the Government of the Russian Federation Moscow, Russian

E-mail: ORozhnova@fal.ru

ORCID ID: 0000-0002-8955-5904 